\title{
The rapid transformation of extracorporeal support in lung transplantation
}

\author{
David D. Odell, MD, MMSc
}

\author{
From the Division of Thoracic Surgery, Surgical Outcomes and Quality Improvement Center, Institute for Public \\ Health and Medicine, Northwestern University, Feinberg School of Medicine, Chicago, Ill \\ Disclosures: Author has nothing to disclose with regard to commercial support. \\ Received for publication Aug 25, 2016; accepted for publication Aug 26, 2016. \\ Address for reprints: David D. Odell, MD, MMSc, Division of Thoracic Surgery, Surgical Outcomes and Quality \\ Improvement Center, Institute for Public Health and Medicine, Northwestern University, Feinberg School of \\ Medicine, Chicago, IL (E-mail: dodell@nm.org). \\ J Thorac Cardiovasc Surg 2016;152:e137-8 \\ $0022-5223 / \$ 36.00$ \\ Copyright (C) 2016 by The American Association for Thoracic Surgery \\ http://dx.doi.org/10.1016/j.jtcvs.2016.08.056
}

Primary allograft dysfunction (PGD) after lung transplantation is a significant concern for transplant surgeons and remains a major cause of near-term mortality. ${ }^{1}$ Fortunately, options for aggressive support of patients with PGD have become more widely available, including extracorporeal membrane oxygenation (ECMO) ${ }^{2-4}$ In the current issue of the Journal, Mehaffey and colleagues ${ }^{5}$ provide longterm follow-up of early use of ECMO, initially reported 14 years ago, for management of post-transplant PGD related to neurogenic pulmonary edema. Although this is itself an isolated case, its publication underscores both the potential for favorable results with aggressive extracorporeal support and the importance of long-term data on functional outcomes for these patient, which are currently lacking in the lung transplant literature.

The use of ECMO in support of lung transplantation has dramatically expanded in the past decade. Favorable outcomes have been reported by a number of centers with extracorporeal support for PGD and other forms of respiratory failure in the post-transplant period. ${ }^{2-4}$ The availability of a viable rescue method also has facilitated broadened definitions of "acceptable donors," thereby increasing the limited supply of donor organs. However, the use of ECMO in lung transplantation has rapidly expanded beyond mere postoperative support. The technology is now frequently used to extend patient viability before transplant until a suitable lung donor becomes available, with several centers demonstrating outcomes similar to those of patients who underwent transplantation with conventional ventilator support. ${ }^{6,7}$ The impact of ECMO on PGD may begin even earlier because ECMO has made the journey into the operating room, replacing conventional cardiopulmonary bypass in many centers. Evolving data indicate this approach may reduce inflammation and limit the development of allograft dysfunction. ${ }^{8,9}$

In their discussion of the case, Dr Mehaffey and colleagues $^{5}$ discuss the potential to expand the lung donor

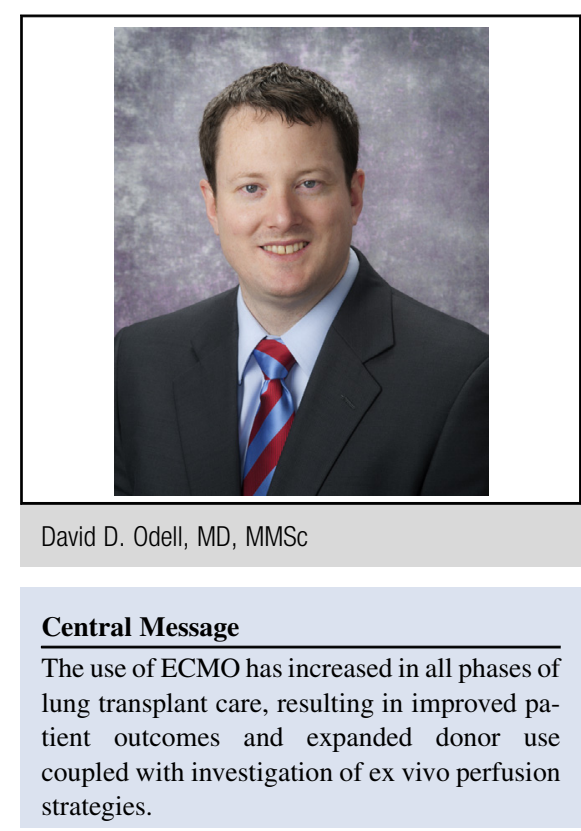

See Article page e135.

pool by improving the use of marginally functioning lungs with the aid of technology such as ECMO to allow for in vivo recovery after transplant. Although this approach may be the state of the art currently, the focus is rapidly shifting toward augmentation of our ability to assess and rehabilitate donor lungs preoperatively. The exploding research and clinical use of ex vivo lung perfusion (EVLP) techniques potentially represent the next giant step forward in the use of extracorporeal technology to improve the field of lung transplantation. Use of EVLP allows a more complete longitudinal assessment of potentially evolving lung injuries, such as aspiration pneumonia or lung contusion, commonly seen in organ donors. Further, effective interventions for these conditions, such as highdose antibiotic treatment for donor pneumonia, may be administered in the EVLP environment without exposing the recipient to the risks associated with both the marginally functioning lung and the treatment of the underlying condition. ${ }^{10}$ As lung transplant surgeons strive to increase donor use while maintaining safe transplant outcomes, expanded use of both ECMO and EVLP is likely to play a critical role, and it will be important to assess the long-term functional outcomes in addition to celebrating the near-term successes. 


\section{References}

1. Christie JD, Kotloff RM, Ahya VN, Tino G, Pochettino A, Gaughan C, et al. The effect of primary graft dysfunction on survival after lung transplantation. Am J Respir Crit Care Med. 2005;171:1312-6.

2. Bermudez CA, Adusumilli PS, McCurry KR, Zaldonis D, Crespo MM, Pilewski JM, et al. Extracorporeal membrane oxygenation for primary graft dysfunction after lung transplantation: long-term survival. Ann Thorac Surg. 2009;87:854-60.

3. Hartwig MG, Walczak R, Lin SS, Davis RD. Improved survival but marginal allograft function in patients treated with extracorporeal membrane oxygenation after lung transplantation. Ann Thorac Surg. 2012;93:366-71.

4. Fischer S, Bohn D, Rycus P, Pierre AF, de Perrot M, Waddell TK, et al. Extracorporeal membrane oxygenation for primary graft dysfunction after lung transplantation: analysis of the Extracorporeal Life Support Organization (ELSO) registry. J Heart Lung Transplant. 2007;26:472-7.

5. Mehaffey JH, Hawkins RB, Charles EJ, Tribble CG. Revisiting successful transplantation with marginal lungs: Fourteen years later, a new era of extended criteria. J Thorac Cardiovasc Surg. 2016;152:e135-6.
6. Hayanga AJ, Aboagye J, Esper S, Shigemura N, Bermudez CA, D’Cunha J, et al. Extracorporeal membrane oxygenation as a bridge to lung transplantation in the United States: an evolving strategy in the management of rapidly advancing pulmonary disease. J Thorac Cardiovasc Surg. 2015; 149:291-6.

7. Toyoda Y, Bhama JK, Shigemura N, Zaldonis D, Pilewski J, Crespo M, et al. Efficacy of extracorporeal membrane oxygenation as a bridge to lung transplantation. J Thorac Cardiovasc Surg. 2013;145:1065-71.

8. Bermudez CA, Shiose A, Esper SA, Shigemura N, D'Cunha J, Bhama JK, et al. Outcomes of intraoperative venoarterial extracorporeal membrane oxygenation versus cardiopulmonary bypass during lung transplantation. Ann Thorac Surg. 2014;98:1936-43.

9. Biscotti M, Yang J, Sonett J, Bacchetta M. Comparison of extracorporeal membrane oxygenation versus cardiopulmonary bypass for lung transplantation. J Thorac Cardiovasc Surg. 2014;148:2410-5.

10. Nakajima D, Cypel M, Bonato R, Machuca TN, Iskender I, Hashimoto K, et al. Ex vivo perfusion treatment of infection in human donor lungs. Am J Transplant. 2016;16:1229-37. 